\title{
Pollinator-friendly Plants: Reasons for and Barriers to Purchase
}

\author{
Benjamin Campbell ${ }^{1,3}$, Hayk Khachatryan ${ }^{2}$, and Alicia Rihn ${ }^{2}$
}

\begin{abstract}
AdDITIONAL INDEX WORDs. consumer survey, information source, tobit model
SUMMARY. Certain pesticides are coming under scrutiny because of their impact on pollinator insects. Although most consumers express willingness to aid pollinators, the reasons for consumers' preferences or barriers to purchasing pollinator-friendly plants and the types of pollinators' that consumers are trying to protect are less understood. Using an online survey of 1200 Connecticut (CT) consumers, of which 841 had home landscapes, we find that $46 \%$ of consumers with home landscapes purchased pollinator-friendly plants to attract pollinators to their landscape. Consistent with past research that focused on consumers' preferences for pollinatorfriendly plants, the data also reveal that some consumers are willing to pay premiums for plants that contribute to pollinator's health. However, only $17 \%$ stated that attracting pollinators was their primary motivation; a finding that suggests labeling alone will likely not motivate consumers to purchase plants. The major barriers to purchasing pollinator-friendly plants included lack of labeling (cited by $\mathbf{2 8 \%}$ ), followed by high price $(\mathbf{2 8 \%})$. Consumers purchasing pollinatorfriendly plants were trying to attract butterflies (Lepidoptera) $(78 \%)$, bees (Apidae) (59\%), hummingbirds (Trochilidae) (59\%), and other birds (41\%). We also find that demographics and purchasing behavior affect barriers and types of pollinators desired. Simply labeling plants has the potential to increase purchasing, but increasing price could be detrimental as many consumers feel pollinator-friendly plants are highly priced. Implications for ornamental horticulture stakeholders are discussed.
\end{abstract}

$\mathrm{R}$ ecent pollinator population decline has become a global concern (Gallai et al., 2009; Goulson et al., 2015; Klein et al., 2007). Pollinator insects are important because they contribute substantially to the global economy and food availability (Gallai et al., 2009; Klein et al., 2007). Klein et al. (2007) estimated that $70 \%$ of 124 global food crops depend on pollinator insects. Another study by Gallai et al. (2009) discussed that without insect pollination, food crops would not sufficiently meet world consumption needs. In 2005 , the annual global value of insect pollination services was $€ 153$ billion for human food crops with fruits and vegetables having the highest value at about $€ 102$ billion (Gallai et al., 2009). Recent pollinator declines

Funding has been provided by the Specialty Crop Block Grant Program of the Agricultural Marketing Service, U.S. Department of Agriculture, awarded and administered by the Connecticut Department of Agriculture.

${ }^{1}$ Department of Agricultural and Applied Economics, University of Georgia, 147 Cedar Street, Athens, GA 30602

${ }^{2}$ Department of Food and Resource Economics, MidFlorida Research and Education Center, University of Florida, 2725 South Binion Road, Apopka, FL 32703

${ }^{3}$ Corresponding author. E-mail: bencamp@uga.edu.

doi: 10.21273/HORTTECH03829-17 have resulted in widespread public concern because of the dependence of food crops on insect pollinators. This has generated research on production-related factors (e.g., pesticides, parasites, disease, urbanization, etc.) that negatively impact pollinator health (Blacquiére et al., 2012; Fairbrother et al., 2014; Hanley et al., 2015; Pimentel, 2005). However, the studies addressing (noncommercial) end consumers, their interest, and their actions to aid pollinators are much more limited.

Several consumer studies related to pollinator insects focused on willingness-to-pay for conservation programs (Breeze et al., 2015; Diffendorfer et al., 2014; Mwebaze et al., 2010). For example, Mwebaze et al. (2010) found UK households were willing to pay $£ 1.37$ /week for a hypothetical beeprotection policy, which equates to $£ 1.77$ billion/year. Similarly, Breeze et al. (2015) determined consumers were willing to pay a total of $£ 379$ million to conserve local produce supplies and wildflower aesthetics for pollinator insects. U.S. consumers were also willing to pay premiums to aid pollinator insects. Diffendorfer et al. (2014) found U.S. consumers were willing to pay a one-time payment of
$\$ 4.78$ billion to $\$ 6.64$ billion to purchase monarch butterfly (Danaus plexippus)-friendly plants and donate to conservation programs. Each of these studies demonstrates that consumers value and want to aid pollinator insects through their gardening practices [such as purchasing monarch butterflyfriendly plants (Diffendorfer et al., 2014)] or through donations to conservation programs (Breeze et al., 2015; Diffendorfer et al., 2014; Mwebaze et al., 2010). However, much less is known about individual-specific actions and preferences related to pollinator insects.

Consumers have specific preferences for and perceptions of horticultural production methods that aid pollinator insects (Getter et al., 2016; Khachatryan and Rihn, 2017; Rihn and Khachatryan, 2016; Wollaeger et al., 2015). Wollaeger et al. (2015) used a nationwide survey to assess U.S. consumer purchase likelihood for floriculture crops grown using different pest management strategies (i.e., traditional, neonicotinoid-free, bee-friendly, biological control). According to their findings, consumers were willing to pay $\$ 0.96$ to $\$ 2.10$ more for plants grown using bee-friendly production methods when compared with traditional practices. Both the neonicotinoid-free and traditional production methods were perceived negatively. Contrary to common expectations, neonicotinoid-free production was perceived and valued most negatively. Wollaeger et al. (2015) hypothesize the negative perceptions of the neonicotinoid-free production practices were a result from low consumer knowledge. Getter et al. (2016) found similar results with bee-friendly production methods obtaining premiums between $\$ 0.26$ and $\$ 1.15$ when compared with other eco-friendly production practices (i.e., "grown in a sustainably produced soil/mix," "grown using recycled/recaptured water," "grown using protective neonicotinoid insecticides," or "grown using traditional" practices). Both studies demonstrate consumers' value of practices to aid pollinator insects.

Consumer awareness of production methods that aid pollinators also influence behavior toward ornamental plants (Rihn and Khachatryan, 2016). Rihn and Khachatryan (2016) assess how consumers' awareness of 
neonicotinoids was related to pollinatorrelated knowledge and pollinator promotion preferences. About, 24\% of the U.S. population was aware of neonicotinoid insecticides. Those who were familiar with the term were more knowledgeable about neonicotinoids and pollinators/pollinator-related topics in general. Neonicotinoid aware consumers were more likely to purchase products labeled as "neonic-free" than individuals who were not aware of neonicotinoids. Awareness also influenced point-of-sale promotion preferences with aware individuals preferring "bee-safe" and "neonic-free" more than those who were unaware. However, despite this increased preference for that terminology, "neonic-free" was not the preferred phrasing for either aware or not aware consumers. Instead, they preferred "pollinatorfriendly," "pollinator-safe," "plants for pollinators," and "bee-friendly." Regarding purchase likelihood, neonicotinoid aware consumers were more likely to purchase a "neonic-free" plant than not aware consumers. Nevertheless, other promotional labels had more impact.

Considering the findings in recent empirical investigations, consumers value pollinator insect conservation programs (Breeze et al., 2015; Diffendorfer et al., 2014; Mwebaze et al., 2010) and horticultural products grown using pollinator-friendly insect management programs (Getter et al., 2016; Khachatryan and Rihn, 2017; Rihn and Khachatryan, 2016; Wollaeger et al., 2015). However, the underlying reasons for their preferences or barriers to purchasing pollinator-friendly plants and the types of pollinators consumers are trying to protect have not been studied. This study addresses this knowledge gap using an online survey of $1200 \mathrm{CT}$ consumers. Notably, we investigate the demographic characteristics and purchasing behaviors that drive preferences for purchasing pollinatorfriendly plants at different types of retailers. Furthermore, we evaluate the types of pollinators that respondents are willing to attract and aid. Finally, we take a brief look at the barriers to purchasing pollinatorfriendly plants.

\section{Data and methods}

An online survey was implemented during the Summer/Fall
2016. The survey covered a host of topics, including perceptions and use of pollinators, genetically modified organisms, and local and organic products. The survey sample constituted of CT residents using Lightspeed Global Market Insite, Inc. (GMI) (Lightspeed Research, Warren, NJ) panel database. CT was chosen given the funding agency's interest in the CT market. Potential respondents were randomly invited from GMI's panel database and those choosing to participate were directed to the survey. The overall completion rate for the survey was $\approx 83 \%$. However, the total number of respondents varied by question given that not all questions were asked of each respondent. For instance, pollinator usage questions were directed at respondents that had purchased a pollinator plant. On the other hand, the pollinator barrier question was posed to all respondents.
The sample was relatively representative of the CT population. However, our sample's median household income and age are similar to that of the CT population (Table $\mathrm{I}$ ). The $\mathrm{CT}$ median age is 40 years (U.S. Census Bureau, 2015), whereas our sample's median age was 46 years. Considering the U.S. Census, median age for CT includes persons less than 18 years of age and our survey only includes respondents more than 18 years of age; our sample is most likely closer to the CT median population than the 6-year difference provided. Median CT household income is $\$ 70,000$ (U.S. Census Bureau, 2011), which is comparable with our sample's median household income of $\$ 75,000$.

To understand the potential drivers of pollinator purchasing at mass merchandiser/home improvement centers and nursery/greenhouse garden centers, we used a two-limit

Table 1. Descriptive statistics of the sample of Connecticut survey respondents who had a home landscape as found by a 2016 survey of Connecticut residents.

\begin{tabular}{lcc}
\hline Variables $^{\mathrm{z}}$ & Mean & SD \\
\hline Median age (years) & 46.0 & - \\
Ethnicity: Caucasian & $86 \%$ & $34 \%$ \\
Gender: male & $27 \%$ & $45 \%$ \\
Political leaning & & \\
$\quad$ Republican & $24 \%$ & $43 \%$ \\
$\quad$ Independent & $38 \%$ & $49 \%$ \\
$\quad$ Other (not democrat) & $9 \%$ & $28 \%$ \\
Urbanicity & & \\
$\quad$ Suburban & $66 \%$ & $28 \%$ \\
$\quad$ Urban & $10 \%$ & 1.04 \\
Adults in household (no.) & 2.30 & 0.98 \\
Children in household (no.) & 0.59 & \\
Household income (median) & 75,000 & $47 \%$ \\
Education level & & $45 \%$ \\
$\quad$ Some college/2-year degree & $35 \%$ & $39 \%$ \\
$\quad$ Bachelors & $28 \%$ & \\
$\quad$ Graduate degree & $18 \%$ & $29 \%$ \\
Environmental information source trust ${ }^{\mathrm{y}}$ & & $30 \%$ \\
$\quad$ University & $70 \%$ & $30 \%$ \\
Industry association & $45 \%$ & $29 \%$ \\
Federal government & $48 \%$ & $27 \%$ \\
$\quad$ Nonprofit & $64 \%$ & $31 \%$ \\
$\quad$ Mass merchandiser & $43 \%$ & \\
$\quad$ Activist group & $64 \%$ & \\
Landscape plants pollinator-friendly (\%) & $45 \%$ & \\
Pollinator plant neighbor comparison & & \\
$\quad$ Less than & & \\
$\quad$ More than & & \\
Observations (no.) & & \\
\hline
\end{tabular}

${ }^{z}$ The base variables included ethnicity $=$ non-Caucasian, political leaning $=$ democrat, urbanicity $=$ rural education $=$ high school/general educational development $($ GED $)$ or less, neighbor comparison $=$ equal.

"Trust was measured on a $0-100$ point scale where $0=$ "distrust," $50=$ "neither trust or distrust," and $100=$ "trust."

${ }^{\mathrm{x}} \mathrm{A}$ total of 1,200 consumers took the survey, but 841 were asked questions about pollinator-friendly plants given the other survey respondents did not have a home landscape. 
tobit model developed by Rossett and Nelson (1975). A pollinator-friendly plant purchasing value was obtained by asking survey respondents what percentage of their plant purchases at a mass merchandiser/home improvement center (and nursery/greenhouse garden center) are pollinator-friendly plants. Of note, it could be the case that some misreporting (under- or overestimating of purchases) may occur, although the extent of any misreporting is unknown. In this context, respondents are limited to a lower $(0)$ and upper limit (100). The two-limit model can be formulated as

$$
\begin{gathered}
y_{\mathrm{i}}^{*}=\beta^{\prime} x_{\mathrm{i}}+\varepsilon_{\mathrm{i}} \quad(i=1, \ldots, n) \\
y_{\mathrm{i}}=\left\{\begin{array}{l}
0 \text { if } y_{\mathrm{i}}^{*} \leq 0 \\
y_{\mathrm{i}}^{*} \text { if } 0<y_{\mathrm{i}}^{*}<100 \quad(i=1, \ldots, n) \\
100 \text { if } y_{\mathrm{i}}^{*} \geq 100
\end{array}\right.
\end{gathered}
$$

where the latent variable $y_{i}^{*}$ is not observed for values less than $0 \%$ and greater than $100 \%, x$ is a matrix of explanatory variables (Tables 1-6), $\beta$ is a coefficient vector, and $\varepsilon$ represents an independently and normally distributed error term with zero mean and variance $\sigma^{2}$. Explanatory variables included age, household income, number of adults and children within the household, education level, and urbanicity. We also included political leaning (e.g., Republican, Democrat, etc.) and amount of trust in different sources of environmental information (e.g., universities, industry associations, nonprofits). Trust in source of environmental information was measured via a $0-100$ point scale where $0=$ "distrust," $50=$ "neither trust or distrust," and 100 = "trust." We report the conditional marginal effects (calculated as the average marginal effect) which are interpretable similar to that of an ordinary least squares regression coefficient. For categorical variables, it is a change in the dependent variable given a move from the base explanatory variable (e.g., female to male). For continuous variables, it is a change in the dependent variable given a one-unit change in the independent variable.

We use a set of binary logit models to assess which variables may explain which pollinators consumers are wanting to attract. The dependent variable was coded as "zero" when the pollinator was not selected and

Table 2. Production practices for survey respondents with a home landscape from a 2016 survey of Connecticut residents as compared by pollinator inclusion within the home landscape.

\begin{tabular}{lccc}
\hline & $\begin{array}{c}\text { Respondent had some } \\
\text { pollinators in } \\
\text { home landscape }\end{array}$ & $\begin{array}{c}\text { Respondent had no } \\
\text { pollinators in home } \\
\text { landscape }\end{array}$ & Mean (sD) \\
\cline { 2 - 4 } Organic production practices & $23 \%$ & $0 \%$ & $* * *$ \\
Integrated pest management & $(42 \%)$ & $0 \%$ & $* * *$ \\
Reduced pesticide use & $8 \%$ & - & $* *$ \\
Observations (no.) & $(27 \%)$ & $21 \%$ & $(42 \%)$ \\
\hline
\end{tabular}

${ }^{\mathrm{z}} \mathrm{A}$ total of 1,200 consumers took the survey; however, the production practice question was only asked of respondents indicating they had a home landscape.

${ }^{* * *}$ represents significance at the $P \leq 0.01$ level using a chi-square test.

"one" when it was selected. For instance, for a respondent who indicated that bees were a pollinator they wanted to attract, the bee variable value was scored a one. The binary logit probability can be formulated as

$$
P(Y=1 \mid X)=\frac{e^{x^{\prime} \beta}}{1+e^{x^{\prime} \beta}}
$$

where $P$ is the respondent's probability of choosing the pollinator, $x$ is a set of explanatory variables (Tables 1-6), and $\beta$ is a coefficient vector (Greene, 2003). We report log odds which are the odds of being in one of the groups.

\section{Results and discussion}

Production practices. To better understand pollinator plant purchasing, an initial objective is to determine if respondents are implementing what could be thought of as pollinator-friendly practices. Based on Table 2, about half of respondents who indicated they had pollinatorfriendly plants in their home landscape state that they have reduced pesticide use in their home landscape. In comparison, significantly fewer (21\%) respondents with no pollinator-friendly plants in their home landscape had reduced pesticide use in their landscape. Furthermore, 23\% of respondents with pollinator-friendly plants in their landscape had moved to organic production practices, whereas only $0 \%$ of respondents with no pollinator-friendly plants had moved to organic production practices.

Purchasing. As can be seen in Table 3, half of respondents cited attracting pollinators as a reason they
Table 3. Connecticut survey respondents with pollinator-friendly plants in their home landscape purchased pollinatorfriendly plants based on the results from a 2016 survey of 1,200 Connecticut residents.

\begin{tabular}{lcc}
\hline & Mean & SD \\
\hline Attract pollinators & $47 \%$ & $50 \%$ \\
Plant a variety of plant types & $50 \%$ & $50 \%$ \\
Like the way they look & $49 \%$ & $50 \%$ \\
Some other reason & $9 \%$ & $28 \%$ \\
Observations (no.) $^{\mathrm{z}}$ & \multicolumn{2}{c}{749} \\
\hline
\end{tabular}

${ }^{\mathrm{z}}$ A total of 1,200 consumers took the survey; however, the production practice question was only asked to respondents indicating they had a home landscape.

use pollinator-friendly plants. Planting a variety of plants and liking the look of pollinator-friendly plants were also cited by half the respondents. This implies that focusing only on the pollinator attraction characteristic of pollinator-friendly plants may not optimize the effect of marketing messages that resonate for many buyers. Given these findings, retailers need to focus on marketing not only the plant's ability to attract pollinators, but also focus on the plant's appearance in the landscape as well as promoting a variety of pollinator plants.

With respect to attracting pollinators, butterflies are the primary pollinator that $78 \%$ of pollinator-friendly buyer respondents seek to attract (Table 4). Bees and hummingbirds are the second most identified pollinator with $60 \%$ and $59 \%$, respectively. Birds rank fourth with bats (Chiroptera) and other pollinators rounding out the list with $11 \%$ each. 
Table 4. Types of pollinators Connecticut survey respondents are trying to attract based on responses from a 2016 survey of 1,200 Connecticut residents.

\begin{tabular}{lcc}
\hline & Mean & SD \\
\hline Bees & $59 \%$ & $49 \%$ \\
Hummingbirds & $59 \%$ & $49 \%$ \\
Butterflies & $76 \%$ & $43 \%$ \\
Birds (excluding & $41 \%$ & $49 \%$ \\
$\quad$ hummingbirds) & & \\
Bats & $11 \%$ & $31 \%$ \\
Other & $11 \%$ & $31 \%$ \\
Observations (no.) ${ }^{\mathrm{z}}$ & \multicolumn{2}{c}{749} \\
\hline
\end{tabular}

${ }^{\mathrm{z}} \mathrm{A}$ total of 1,200 consumers took the survey; however, the production practice question was only asked of respondents indicating they had a home landscape.

In this vein, consumers perceive that they are purchasing a large amount of pollinator-friendly plants from mass merchandiser/home improvement centers and nursery/ greenhouse garden centers (Table 5). For instance, $42 \%$ of consumers perceive their plant purchases at a mass merchandiser/home improvement center were pollinator-friendly plants. However, $54 \%$ of plants purchased at a nursery/greenhouse garden center were perceived as pollinator-friendly. This percentage is lower than that of local and native, but in-line with the percentage purchased that were perceived to be organic. Our findings that a relatively large number of respondents indicate they are reducing pesticide use in their landscape (Table 2) in conjunction with the relatively large percentage of pollinator-friendly plants respondents indicate their purchasing (Table 5) is consistent with the findings of Khachatryan and Rihn (2017). Khachatryan and Rihn (2017) found that consumers perceive reducing pesticides is a good way to increase pollinator health.

Also of interest, we find that consumers perceive they are purchasing more local, native, pollinator-friendly, and organic plants at nursery/greenhouse garden centers compared with home improvement center/mass merchandisers. The reason for this is not known. A plausible explanation could be that nursery/greenhouse garden centers are more specialized in marketing plants as local, organic, native, or pollinator-friendly. However, an equally valid reason could be that consumers are more likely to assume

Table 5. Perceived percentage of plant types purchased by Connecticut survey respondents who purchased plants in the last 3 years at varying retail outlets based on responses from a 2016 survey of 1,200 Connecticut residents. ${ }^{\mathrm{z}}$

\begin{tabular}{|c|c|c|c|c|}
\hline & \multicolumn{2}{|c|}{$\begin{array}{c}\text { Home improvement } \\
\text { center } / \text { mass merchandiser }\end{array}$} & \multicolumn{2}{|c|}{$\begin{array}{l}\text { Nursery/greenhouse } \\
\text { garden center }\end{array}$} \\
\hline & Mean & SD & Mean & SD \\
\hline Local & $49 \%$ & $29 \%$ & $69 \%$ & $28 \%$ \\
\hline Native & $47 \%$ & $28 \%$ & $64 \%$ & $29 \%$ \\
\hline Pollinator-friendly & $42 \%$ & $28 \%$ & $54 \%$ & $30 \%$ \\
\hline Organic & $39 \%$ & $30 \%$ & $53 \%$ & $32 \%$ \\
\hline Observations (no. $)^{\mathrm{y}}$ & \multicolumn{2}{|c|}{841} & \multicolumn{2}{|c|}{844} \\
\hline
\end{tabular}

${ }^{z}$ The question was as follows, "When shopping at a home improvement center/mass merchandiser (nursery/ greenhouse garden center), what percentage of your plant purchases are..." where respondents clicking on a $0-100$ point scale the amount of purchases that were local, native, pollinator-friendly, and organic.

${ }^{y}$ A total of 1,200 consumers took the survey; however, the production practice question was only asked of respondents indicating they had a home landscape.

(either correctly or incorrectly) that plants are local, organic, native, or pollinator-friendly at a nursery/ greenhouse garden center compared with plants purchased at a home improvement center/mass merchandiser. This could be the result of varying definitions both real and perceived for these terms. For instance, there is no definitive definition for pollinatorfriendly. Respondents may be thinking of a plant that attracts pollinators, a plant that does not harm a pollinator, or a plant that is neonicotinoid-free. The reason for the perception that more local, organic, native, or pollinator-friendly purchased at nursery/ greenhouse garden centers would dictate how firms should react. If nursery/greenhouse garden centers are better at marketing their plants or offering plants not offered by home improvement center/mass merchandiser then this is a niche that should be catered too. However, if respondents only perceived increased purchasing of these plant types at nursery/greenhouse garden centers, then this creates issues for both types of retailers. Home improvement center/mass merchandisers may be investing in products with specific production practices or offering plants that are local, organic, etc., but consumers are not noticing. Nursery/ greenhouse garden centers may be selling plants that are being afforded attributes they may not have. If consumers are incorrectly perceiving they are purchasing these types of plants and they are not, then nursery/ greenhouse garden centers, as well as home improvement centers/mass merchandisers, need to better educate their clientele so that consumers do not
Table 6. Barriers to purchasing more pollinator-friendly plants by Connecticut survey respondents who have pollinator-friendly plants in their home landscapes based on responses from a 2016 survey of 1,200 Connecticut residents.

\begin{tabular}{lcc}
\hline Barrier & Mean & SD \\
\hline High price & $28 \%$ & $45 \%$ \\
Lack the products I want & $20 \%$ & $40 \%$ \\
Quality issues & $12 \%$ & $32 \%$ \\
Not labeled & $34 \%$ & $48 \%$ \\
Lack of unique plants & $17 \%$ & $38 \%$ \\
Do not carry & $16 \%$ & $37 \%$ \\
Marketing gimmick & $7 \%$ & $25 \%$ \\
Other & $20 \%$ & $40 \%$ \\
Observations (no.) $^{\mathrm{z}}$ & \multicolumn{2}{c}{855} \\
\hline
\end{tabular}

${ }^{\mathrm{z}}$ A total of 1,200 consumers took the survey; however, the production practice question was only asked of respondents indicating they had a home landscape.

lose trust if they find out they are incorrect in their assumptions.

BARRIERS TO PURCHASING. "Not labeling pollinator-friendly plants" was the most cited reason for not purchasing more pollinator-friendly plants (Table 6). About one-third (34\%) of respondents identified labeling as a reason for not purchasing more pollinator-friendly plants. Seven percent of respondents in our survey perceived pollinator-friendly plants as a marketing gimmick. "Higher prices" was cited by $28 \%$ of respondents as limiting their pollinator plant purchasing. This implies that $72 \%$ of respondents did not find higher prices as a limiting barrier. However, before charging higher prices, retailers need to consider the amount of effort and resources they will be using to brand or differentiate the pollinator-friendly label. Retailers who are able to brand 
Table 7. Tobit conditional marginal effects for percent pollinator-friendly plant purchases by retailer type based on responses from a 2016 survey of 1,200 Connecticut residents.

\begin{tabular}{|c|c|c|c|c|}
\hline \multirow[b]{3}{*}{ Variables } & \multicolumn{4}{|c|}{$\begin{array}{l}\text { Mass merchandiser/home improvement } \\
\text { center }\end{array}$} \\
\hline & \multicolumn{4}{|c|}{ Conditional marginal effects ${ }^{\mathrm{z}}$} \\
\hline & Coefficient & $P$ value & Coefficient & Pvalue \\
\hline Age (years) & -0.17 & 0.004 & -0.10 & 0.071 \\
\hline Ethnicity: Caucasian & -4.97 & 0.026 & -6.15 & 0.008 \\
\hline Gender: male & 1.56 & 0.405 & -1.43 & 0.424 \\
\hline \multicolumn{5}{|l|}{ Political leaning } \\
\hline Republican & 2.41 & 0.299 & 0.83 & 0.731 \\
\hline Independent & -2.95 & 0.138 & -1.00 & 0.623 \\
\hline Other (not democrat) & 0.77 & 0.822 & -4.11 & 0.238 \\
\hline \multicolumn{5}{|l|}{ Urbanicity } \\
\hline Suburban & 0.53 & 0.783 & 0.10 & 0.960 \\
\hline Urban & 0.01 & 0.998 & 3.19 & 0.342 \\
\hline Adults in household (no.) & -0.38 & 0.650 & 0.13 & 0.867 \\
\hline Children in household (no.) & 0.32 & 0.691 & 0.38 & 0.643 \\
\hline Household income & 0.00 & 0.795 & 0.00 & 0.347 \\
\hline \multicolumn{5}{|l|}{ Education level } \\
\hline Some college/2-year degree & -2.84 & 0.247 & -0.26 & 0.917 \\
\hline Bachelors & -2.81 & 0.272 & -3.91 & 0.122 \\
\hline Graduate degree & -5.15 & 0.075 & -4.29 & 0.135 \\
\hline \multicolumn{5}{|l|}{ Environmental information source trust } \\
\hline University & -0.02 & 0.541 & 0.07 & 0.018 \\
\hline Industry association & 0.06 & 0.040 & -0.01 & 0.865 \\
\hline Federal government & 0.03 & 0.283 & -0.01 & 0.864 \\
\hline Nonprofit & -0.01 & 0.781 & 0.02 & 0.547 \\
\hline Mass merchandiser & 0.06 & 0.078 & 0.02 & 0.505 \\
\hline Activist group & 0.02 & 0.569 & -0.01 & 0.746 \\
\hline Landscape plants pollinator-friendly (\%) & 0.19 & 0.000 & 0.17 & 0.000 \\
\hline \multicolumn{5}{|l|}{ Pollinator plant neighbor comparison } \\
\hline Less than & -1.04 & 0.645 & -1.13 & 0.615 \\
\hline More than & 0.20 & 0.917 & -2.11 & 0.278 \\
\hline \multicolumn{5}{|l|}{ Current landscaping practices } \\
\hline Organic & 5.11 & 0.009 & 9.71 & 0.000 \\
\hline Integrated pest management & -2.54 & 0.386 & 3.58 & 0.198 \\
\hline Reduced pesticide use & -0.02 & 0.991 & 0.44 & 0.797 \\
\hline \multicolumn{5}{|l|}{ Reasons to purchase } \\
\hline Attract pollinators & 5.85 & 0.001 & 5.74 & 0.002 \\
\hline Like to plant variety & 1.70 & 0.322 & 1.44 & 0.399 \\
\hline Like look of pollinators & -0.83 & 0.632 & -1.20 & 0.488 \\
\hline Other & 3.31 & 0.351 & -1.24 & 0.716 \\
\hline \multicolumn{5}{|l|}{ Barriers to purchase more } \\
\hline High price & 1.00 & 0.609 & -2.02 & 0.320 \\
\hline Lack the products I want & 2.65 & 0.163 & 2.11 & 0.298 \\
\hline Quality issues & 8.41 & 0.001 & 4.73 & 0.068 \\
\hline Not labeled & -4.14 & 0.028 & -1.37 & 0.460 \\
\hline Lack of unique plants & -0.88 & 0.662 & 1.53 & 0.457 \\
\hline Do not carry & 2.09 & 0.334 & -0.59 & 0.774 \\
\hline Marketing gimmick & -3.78 & 0.221 & -4.64 & 0.154 \\
\hline Other & -7.42 & 0.006 & -4.24 & 0.100 \\
\hline \multicolumn{5}{|l|}{ Overall model fit } \\
\hline $\operatorname{Sigma}^{\mathrm{y}}$ & \multicolumn{2}{|c|}{26.7} & \multicolumn{2}{|c|}{30.9} \\
\hline Sigma confidence interval ${ }^{y}$ & \multicolumn{2}{|c|}{$(24.9,28.6)$} & \multicolumn{2}{|c|}{$(28.6,33.2)$} \\
\hline Left censored ${ }^{y}$ & \multicolumn{2}{|c|}{$13 \%$} & \multicolumn{2}{|c|}{$9 \%$} \\
\hline Right censored ${ }^{y}$ & \multicolumn{2}{|c|}{$2 \%$} & & \\
\hline Observations (no. $)^{x}$ & & & & \\
\hline Log pseudo likelihood ${ }^{y}$ & & & & \\
\hline
\end{tabular}


Table 7. (Continued) Tobit conditional marginal effects for percent pollinator-friendly plant purchases by retailer type based on responses from a 2016 survey of 1,200 Connecticut residents.

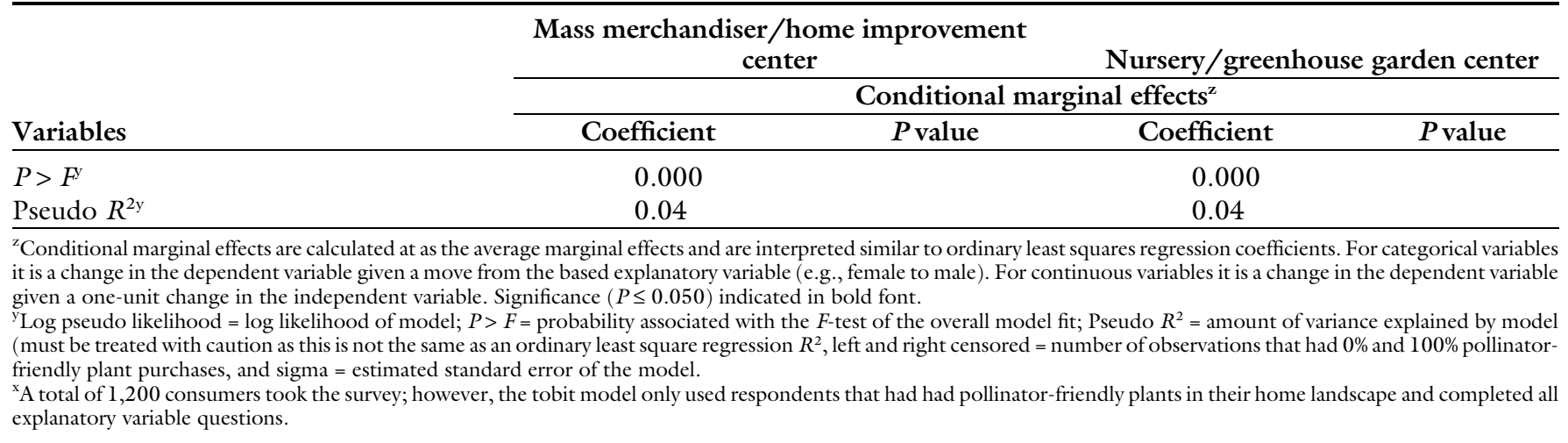

the pollinator-friendly label as a positive, value-added component to the plant may be able to create a more inelastic demand curve, thereby creating more revenue via higher prices (Palma et al., 2012). However, retailers who are not able to create increased label value may be blunting sales volume by charging premiums. Given recent findings that ornamental plant demand is elastic (Hovhannisyan and Khachatryan, 2017), increasing prices would result in lower revenue overall with an elastic demand curve. Thereby, pricing needs to be considered in conjunction with efforts to promote the pollinator-friendly plant label.

TWO-LIMIT TOBIT MODEL: Pollinator purchasing. Using the two-limit tobit model, we gain a better understanding of the drivers of pollinator-friendly plant purchasing which comprises a large percentage of plant purchasing. In the mass merchandiser/home improvement center model, we find that older consumers are less likely to purchase pollinatorfriendly plants (Table 7). Furthermore, Caucasian consumers are less likely to purchase pollinator-friendly plants. However, respondents who trust industry associations and mass merchandisers are more likely to purchase pollinator-friendly plants. Respondents who use organic production practices in their landscapes, want to attract more pollinators, and consider quality issues as a barrier to purchasing more pollinator-friendly plants are more likely to purchase pollinatorfriendly plants.

With respect to the nursery/ greenhouse garden center model, greater age and Caucasian ethnicity are correlated with reduced pollinator-friendly plant purchases. Trust in university environmental information is significant in increasing pollinatorfriendly plant purchases. Respondents that use organic landscaping practices and want to attract pollinators are more apt to purchase more pollinatorfriendly plants. Interestingly, trust in industry associations is not a significant driver for pollinator plant purchasing at a nursery/greenhouse garden center.

There are several important takeaways observed through the mass merchandiser/home improvement centers nursery/greenhouse garden center models. First, older consumers were less likely to purchase pollinatorfriendly plants. Whether this tendency is driven by a lack of ecological knowledge is a potential issue for many retailers as the primary consumer group of these plants is expected to be older (Baldwin, 2015; Butterfield, 2004; Dennis and Behe, 2007). Targeting pollinatorfriendly plants to older consumers may result in advertising that does not resonate with this group, thereby leading to decreased sales. However, retailers may experience increased benefits by targeting pollinatorfriendly plants to younger clientele or to new customers. Second, the source of environmental information will play a significant role in shaping some consumer's purchasing of pollinator-friendly plants. A caveat to these results is that this study only surveyed residents of CT so extrapolating the aforementioned recommendations should keep this in mind.

BINARY LOGIT MODELS : Pollinator attraction. Retailers who can effectively convey which plants are pollinator-friendly are better positioned to drive sales. As such, keeping plants in stock that attract specific types of pollinators can be an effective strategy given that consumers want to attract different pollinators. For instance, respondents who want to attract bees rely heavily on the source of environmental information (Table 8). As trust and credibility increases for university and nonprofit sources, a respondent's odds of wanting to attract bees increases. Thereby, a retailer selling plants that attract bees could tout university and nonprofit information, while staying away from information provided by industry associations and activist groups. This response trend is also evident for hummingbirds and butterflies. Retailers selling hummingbird-attracting plants should promote information generated by nonprofit groups, whereas butterfly attracting plants' promotional messages should highlight universitysourced information.

Considering demographic characteristics of the sample, males were less likely to purchase plants that attract hummingbirds and butterflies. On the other hand, respondents in suburban and urban areas were less likely than rural respondents to want pollinator plants that attract hummingbirds. Older consumers were more likely to want pollinatorfriendly plants that attract birds (excluding hummingbirds). As can be seen by the demographic results, retailers need to be wary of developing blanket marketing strategies and would benefit by providing a more "individualized" message that is more meaningful to different consumers.

\section{Conclusions}

This study examined a number of issues associated with pollinator-friendly 


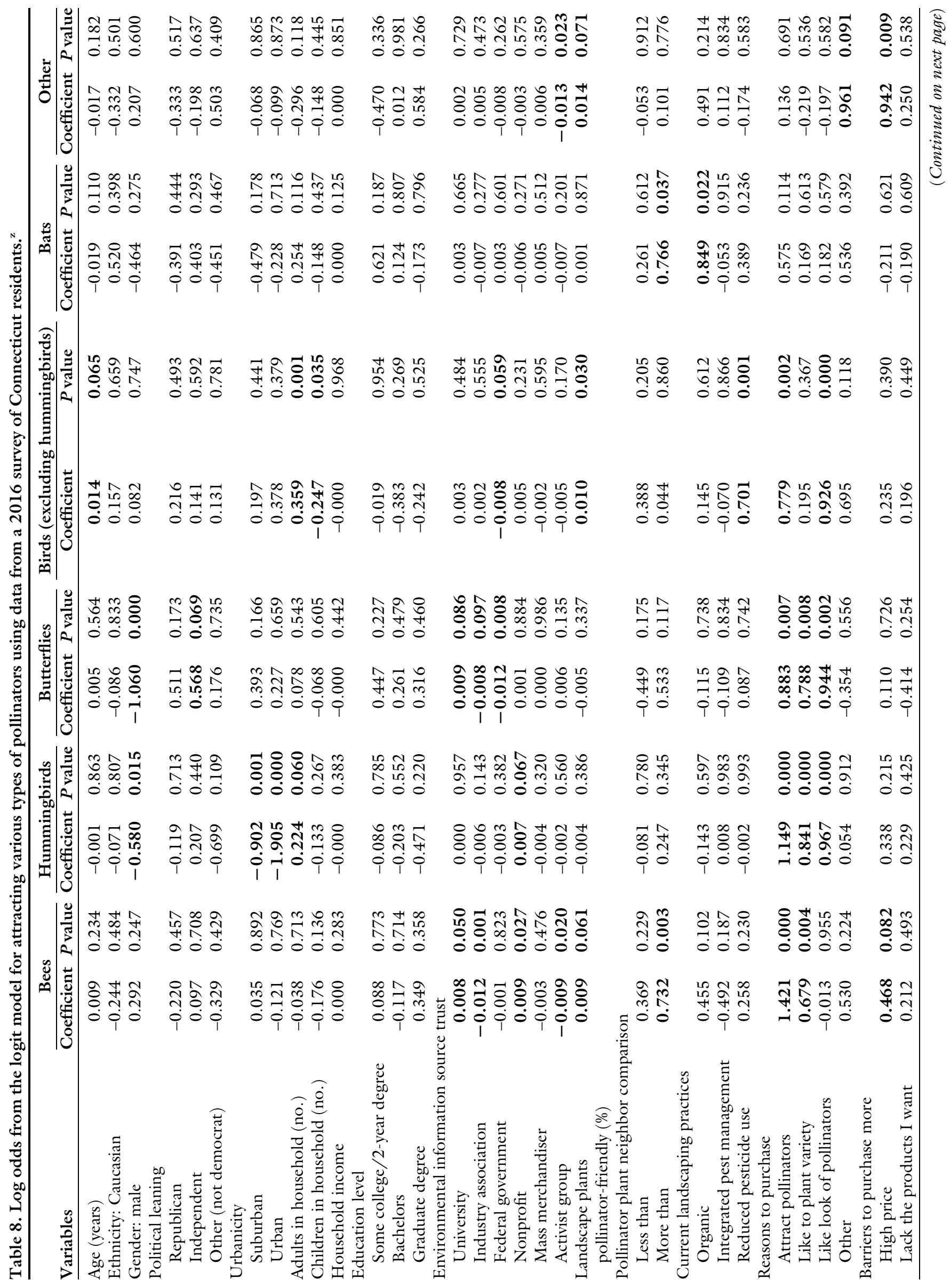


plants. First, pollinator-friendly plants make up a substantial portion of plant purchases, yet the wide belief that purchasing these plants to attract pollinators is inaccurate for half of consumers. Many consumers are purchasing these products because of the desire for a variety of plants and the way pollinator-friendly plants look. Retailers need to use this information within their marketing campaigns to address many consumers' reasons for purchasing.

Retailers should also pay close attention to their clientele because demographics and sources identified as primarily background play a role in driving pollinator-friendly plant purchases. Notably, age and gender influences who purchases these plants and, thereby, should be accounted for in marketing campaigns. Highlighting information sources, such as universities for nursery/greenhouse garden centers and industry association information for mass merchandiser/ home improvement centers, could enhance the messaging associated with purchasing pollinator-friendly plants. Furthermore, realizing that the type of pollinator being attracted is driven by demographics and trust in the source of information. Retailers in non-rural areas should focus less on plants designed to attract pollinators, whereas retailers with older clientele are more likely to have customers wanting plants that attract birds (excluding hummingbirds). As with plant purchasing, information source trust is important in facilitating consumers wanting to attract certain pollinators. Notably, retailers should use information sources valued by consumers in their messaging/advertising. For instance, citing university information will appeal to consumers who want to attract bees.

Finally, retailers face a conundrum as research has shown consumers are willing to pay a price premium for pollinator-friendly attributes. However, higher prices was identified by $28 \%$ of our respondents as a barrier to purchasing more pollinator-friendly plants. Understanding there is a trade-off with higher prices is essential. Higher prices may increase the margin for pollinator-friendly plants, but it 
may also decrease sales as a lower price might allow for increased volume at a lower margin. At the very least, retailers who want to increase pollinatorfriendly plant sales should label these plants as lack of labeling was the number one barrier to purchasing pollinator-friendly plants.

\section{Literature cited}

Baldwin, I. 2015. National gardening survey highlights need for change in retail industry. Today's garden center. 12 Jan. 2017. <http://ianbaldwin.com/ wordpress/wp-content/uploads/2012/ 06/NGS_2014NeedForChangeinRetail Industry.pdf $>$.

Blacquiére, T., G. Smagghe, C.A.M. van Gestel, and V. Mommaerts. 2012. Neonicotinoids in bees: A review on concentrations, side-effects and risk assessment. Ecotoxicology 4:973-992.

Breeze, T.D., A.P. Bailey, S.G. Potts, and K.G. Balcombe. 2015. A stated preference valuation of the non-market benefits of pollination services in the UK. Ecol. Econ. 111:76-85.

Butterfield, B.W. 2004. National gardening association survey 2003. Natl. Gardening Assn., Burlington, VT.

Dennis, J.H. and B.K. Behe. 2007. Evaluating the role of ethnicity on gardening purchases and satisfaction. HortScience 42:262-266.

Diffendorfer, J.E., J.B. Loomis, L. Ries, K. Oberhauser, L. Lopez-Hoffman, D. Semmens, B. Semmens, B. Butterfield, K. Bagstad, J. Goldstein, R. Widerholt, B. Mattsson, and W.E. Thogmartin. 2014. National valuation of monarch butterflies indicates an untapped potential for incentive-based conservation. Conserv. Lett. 7:253-262.

Fairbrother, A., J. Purdy, T. Anderson, and R. Fell. 2014. Risks of neonicotinoid insecticides to honeybees. Environ. Toxicol. Chem. 33:719-731.

Gallai, N., J.-M. Salles, J. Settele, and B.E. Vaissiere. 2009. Economic valuation of the volunerability of world agriculture confronted with pollinator decline. Ecol. Econ. 68:810-821.

Getter, K.L., B.K. Behe, and H.M. Wollaeger. 2016. Comparative consumer perspectives on eco-friendly and insect management practices on floriculture crops. HortTechnology 26:46-53.

Goulson, D., E. Nicholls, C. Botias, and E.L. Rotheray. 2015. Bee decline driven by combined stress from parasites, pesticides, and lack of flowers. Science 347:125597.

Greene, W. 2003. Econometric analysis. 2nd ed. Pearson Educ., Upper Saddle River, NJ.

Hanley, N., T.D. Breeze, C. Ellis, and D. Goulson. 2015. Measuring the economic value of pollination services: Principles, evidence and knowledge gaps. Ecosyst. Serv. 142:137-143.

Hovhannisyan, V. and H. Khachatryan. 2017. Ornamental plants in the United States: An econometric analysis of a household-level demand system. Agribusiness Intl. J. 33:226-241.

Khachatryan, H. and A. Rihn. 2017. Consumer perceptions of plant production practices that aid pollinator insects' health. HortScience 52:749-755.

Klein, A.-M., B.E. Vaissière, J.H. Cane, I. Steffan-Dewenter, S.A. Cunningham, C. Kremen, and T. Tscharntke. 2007. Importance of pollinators in changing landscapes for world crops. Proc. Biol. Sci. 274:303-313.

Mwebaze, P., G.C. Marris, G.E. Budge, M. Brown, S.G. Potts, T.D. Breeze, and A. Macleod. 2010. Quantifying the value of ecosystem services: A case study of honeybee population in the UK. 27 Oct.
2017. <http://centaur.reading.ac.uk/ 24838/1/Mwebaze_et_al_2010_UK_ honeybee_pollination_valuation.pdf $>$.

Palma, M., B.K. Behe, and C. Hall. 2012. Low prices do not sell more plants. 27 Oct. 2017. <http://www.greenhousegrower. $\mathrm{com} / \mathrm{management} / \mathrm{retailing} /$ low-pricesdo-not-sell-more-plants $/>$.

Pimentel, D. 2005. Environmental and economic costs of the application of pesticides primarily in the United States. Environ. Dev. Sustain. 7:229-252.

Rihn, A. and H. Khachatryan. 2016. Does consumer awareness of neonicotinoid pesticides influence their preferences for plants? HortScience 51:388-393.

Rossett, R.N. and F.N. Nelson. 1975. Estimation of the two-limit probit regression model. Econometrica 43:141-146.

U.S. Census Bureau. 2011. State and county quickfacts: Connecticut. 24 Jan. 2017. <http://quickfacts.census.gov/ qfd/states/09000.html>.

U.S. Census Bureau. 2015. Census bureau releases 2010 census demographic profiles for Alaska, Arizona, California, Connecticut, Georgia, Idaho, Minnesota, Montana, New Hampshire, New York, Ohio, Puerto Rico and Wisconsin. 10 Jan. 2017. <https://www.census.gov/ newsroom/releases/archives/2010_ census/cbll-cnl37.html $>$.

Wollaeger, H.M., K.L. Getter, and B.K. Behe. 2015. Consumer preferences for traditional, neonicotinoid-free, beefriendly, or biological control pest management practices on floriculture crops. HortScience 50:721-732. 